http://dx.doi.org/10.12795/RAA.2017.13.05

\title{
CÓRDOBA: GENTE SIN CASA Y BANCOS CON CASAS SIN GENTE. Transformar en viviendas inmuebles desocupados: exclusión y desesperación, transgresión cívica y empoderamiento.
}

José María Manjavacas Ruiz

Universidad de Córdoba

Grupo de investigación GEISA

\section{Resumen.}

En la ciudad de Córdoba (Andalucía) han proliferado casos de familias que, sin vivienda ni recursos para acceder a ella, han optado por el realojo en inmuebles desocupados propiedad de entidades financieras $u$ otras grandes corporaciones. Estas acciones, que los medios más influyentes silencian o tergiversan, discurren al margen de la normalidad urbana pero denuncian una severa crisis habitacional vinculada, por un lado, a la exclusión social y el empobrecimiento; por otro, a la falta de alquiler social, la especulación inmobiliaria y al acaparamiento por parte de grandes corporaciones de miles de inmuebles vacíos. Ha sido estudiada en profundidad una muestra de estas familias, de sus situaciones sociodemográficas y sus motivaciones, de su estado formal en los inmuebles objeto de realojo y de unos procesos personales y colectivos que, vinculados a la plataforma 15M Stop Desahucios, transitan del desamparo y la desesperación al apoyo mutuo, la politización y el empoderamiento. Procesos en los que destaca la decidida actitud de algunos grupos de mujeres en defensa de "un techo" para sus hijas e hijos.

Palabras clave.

Crisis habitacional, Derecho a la vivienda, Realojos, Stop Desahucios. 
Córdoba: Homeless people and bank-owned property. Turning empty housing into homes: Exclusion and hopelessness, breach of civic rights and real estate ownership.

\begin{abstract}
.
A large number of families in Cordoba (Andalusia) are currently homeless. Lacking the financial needs to afford a roof over their heads, they have turned to occupying empty houses which are owned by financial entities or other major corporations. These measures - often ignored or manipulated by the major media outlets - are not what we consider the accepted urban norm, but they call attention to a serious crisis which affects the city's living environment. Social exclusion and impoverishment are some of the reasons for this phenomenon, but also the lack of social housing rents, the rules of real estate speculation, and the hoarding of thousands of empty buildings by major corporations.

We have carried out an exhaustive sample study of some of these families, their sociodemographic and motivational settings, the way they inhabit the disused buildings, and their personal and collective circumstances. In the framework of the 15M Stop Evictions Platform, they have striven to lend each other mutual support, turning to political activism as a means to remedy their situation. In particular, it is worth underlining the extraordinary resilience showed by some groups of women seeking to provide their daughters and sons with a proper home.
\end{abstract}

Keywords.

Housing crisis, Housing rights, Occupation, Stop Evictions.

\title{
1. INTRODUCCIÓN
}

En mayo de 2017, coincidiendo con el Festival de Patios, en la céntrica placita de Las Cañas, junto a la Plaza de la Corredera, tres familias -dos parejas jóvenes y una mujer también joven, en los tres casos con menores- abrían su patio: "un patio cordobés por la vivienda digna". Apenas dos años antes, estas familias, sin vivienda ni recursos para poder costearla, habían accedido al inmueble, propiedad del Banco de Santander, que había sido un hostal y llevaba años abandonado y en desuso, con la intención de adecentarlo y quedarse a vivir en él. "Abrir el patio" fue una fiesta.

En Córdoba, como en otras ciudades, familias sin recursos han optado, ante la falta de viviendas, por habitar inmuebles desocupados. El fenómeno es presentado por algunos medios de comunicación sin atender a sus motivaciones estructurales o a la diversidad de situaciones que conlleva, ocultando que estos realojos, en particular los apoyados 
por grupos de defensa del derecho a la vivienda, se producen en inmuebles, a veces abandonados, que son propiedad de entidades financieras $u$ otras grandes corporaciones, en algunos casos objeto de desahucio. ${ }^{1}$ Raras veces trascienden datos sobre el número de inmuebles vacíos y su propiedad, el carácter especulativo del mercado inmobiliario, la falta de alternativas habitacionales para un sector de población, la intransigencia de algunas entidades privadas o la extrema situación socioeconómica y de desamparo legal y político de quienes, a falta de otras soluciones, emprenden unas acciones que pueden ser tipificadas como delito.

Es la primera cuestión planteada en el marco de una investigación llevada a cabo en la ciudad de Córdoba ${ }^{2}$ : qué hay tras estas acciones que suscitan tal tratamiento en la prensa más influyente mientras grupos por el derecho a la vivienda $u$ otros espacios alternativos hacen otras lecturas bien diferentes. Documentar y analizar suficiente base empírica se convertía en objetivo central, lo cual nos situaba ante un segundo problema: cómo obtener información de primera mano, sobre el terreno, de un fenómeno poco conocido y recluido en los márgenes de la normalidad urbana.

Ambos interrogantes, tomados como problemas de investigación, nos situaron ante el método etnográfico para documentar y posibilitar el análisis del que hicimos nuestro objeto de estudio: el fenómeno de los realojos por parte de personas y familias sin recursos económicos, en Córdoba, en inmuebles sin uso propiedad de entidades financieras. ${ }^{3}$

La etnografía ha posibilitado documentar perfiles sociodemográficos y motivaciones de sesenta unidades familiares que, por los criterios con que han sido seleccionadas, cabe tomar como significativas, pues la muestra ha sido confeccionada en el campo, en base

1. Afirmaciones como "crecimiento alarmante de las ocupaciones de pisos", actuación de "redes delictivas" o de "mafias", "miedo entre los vecinos", "problemas de seguridad y salubridad", etc. La propia alcaldesa de Córdoba, Isabel Ambrosio, hubo de declarar públicamente que "no hay ningún efecto llamada" para la ocupación de pisos vacíos. En la misma rueda de prensa, el subdelegado del Gobierno en Córdoba negó "la existencia de mafias" o de "una oleada organizada de ocupaciones". Ambas autoridades respondían así a noticias difundidas por algunos medios y otros representantes políticos locales. Cordópolis, 26 de abril de 2016. (http://cordopolis.es/2016/04/26/el-subdelegado-descarta-una-oleada-de-ocupacionde-casas/. Consulta: 22/XI/2016). La presión es tal, presentada de manera cíclica a través de rondas de noticias, que Stop Desahucios ha debido desmarcarse públicamente los "los casos de falta de civismo, tráfico de drogas, mercadeo de vivienda y cualquier otro acto delictivo" que nada tienen que ver con "los realojos (de viviendas vacías pertenecientes a entidades bancarias) por parte de familias que no cuenten con recursos económicos suficientes ni tengan otra alternativa habitacional". Diario Córdoba, 15 de julio de 2017. http://www.diariocordoba.com/noticias/cordobalocal/stop-desahucios-desvinculacomportamientos-perjudiciales-viviendas-ocupadas_1159830.html. Consulta: 15/VII/2017).

2. Proyecto "Familias realojadas en inmuebles de entidades financieras". Grupo Municipal Ganemos del Ayuntamiento de Córdoba - ETNOCÓRDOBA-Universidad de Córdoba. Contrato de investigación. Investigador responsable: José María Manjavacas Ruiz. 2016-2017.

3. Se ha optado por el uso de "realojo" para referir estas prácticas siguiendo a Stop Desahucios y a las propias familias implicadas, quienes evitan el término "ocupación" habitual en los medios. 
al conocimiento facilitado por actores cualificados. Ha sido estudiado un grupo, el más numeroso, de familias realojadas que enfrentan un proceso judicial o han logrado -o están negociando- un alquiler social. Por otro lado, otras familias que acordaron -o se encuentran negociando- la dación en pago y un alquiler social en la que fue su propia vivienda. Otros casos incluyen la permanencia en un piso compartido en alquiler social y varias situaciones de hacinamiento. ${ }^{4}$

El trabajo de campo se ha desarrollado de octubre de 2016 a marzo de 2017 entre las personas y colectivos estudiados: familias e instituciones locales y tejido asociativo que apoya a las personas afectadas, y ha incluido distintas modalidades de observación directa en inmuebles, grupos de apoyo mutuo y otras actividades de 15M Stop Desahucios. Se ha prestado particular atención a las situaciones de las familias a partir de sus narraciones, realizando un total de 72 entrevistas a diferentes informantes: 60 a personas que encabezan las familias, 3 con responsables de la Oficina Municipal en Defensa de la Vivienda o de la Empresa Municipal de Vivienda de Córdoba VIMCORSA, 2 con autoridades locales de Vivienda y Servicios Sociales, 4 con activistas sociales, 2 con especialistas universitarios y 1 con un representante del grupo municipal Ganemos. También fueron elaborados cuestionarios cerrados con cada familia con datos sobre el estado de los realojos e inmuebles y otros de carácter sociodemográfico.

Tras esta introducción se esboza la crisis habitacional, general y local, atendiendo a las causas socioeconómicas y políticas que la han generado. A continuación, se muestran datos sobre la propiedad de los inmuebles y la situación de las familias que los han transformado en sus viviendas, mostrando también, a través de experiencias de sus protagonistas, algunos pasajes recurrentes en los realojos: procedimientos habituales, vivencias, actuaciones ante las autoridades... Un conjunto de consideraciones finales reparan, a modo de conclusión, en la dimensión transgresora de estas acciones, la incidencia de la acción política en el crecimiento y empoderamiento, personal y colectivo, de las personas implicadas, las prácticas de apoyo mutuo y, de manera particular, el destacado papel desempeñado por algunos grupos de mujeres.

4. La muestra y nuestro estudio, no atiende por tanto a otros casos de "ocupación" que pudieran venir dándose en la ciudad; se centra en familias realojadas en inmuebles desocupados de entidades financieras que de una u otra forma están vinculadas con la plataforma Stop Desahucios.

5. Ganemos Córdoba, grupo municipal que encargó el estudio, constituye una expresión de las candidaturas municipalistas de base ciudadana surgidas en las últimas elecciones locales. Sus principios se fundamentan en la defensa del derecho a la ciudad, el ecologismo político y el comunitarismo, así como en otras demandas y aspiraciones de los nuevos movimientos sociales y de colectivos y movilizaciones locales registradas en los últimos años. Fue impulsada por miembros de EQUO, Frente Cívico y Podemos, así como por otras personas que han destacado en el activismo político y social de Córdoba, en algunos casos con dilatada trayectoria. Su portavoz en el Ayuntamiento, Rafael Blázquez, ha sido un destacado miembro de la plataforma 15M Stop Desahucios. Para más información puede consultarse Manjavacas (2017). 


\section{EMPOBRECIMIENTO, EXCLUSIÓN SOCIAL, NEGACIÓN DEL DERECHO A LA VIVIENDA Y CRISIS HABITACIONAL}

La crisis económica y financiera y la explosión de la burbuja inmobiliaria supusieron la quiebra del modelo de crecimiento económico, trasladando a amplios sectores de la población un empeoramiento de sus condiciones de vida. El cierre de empresas, el crecimiento del desempleo -y del subempleo y el empleo precarizado-, la reducción de salarios y la desregulación de las relaciones laborales han cursado en un marco de transferencia de rentas del trabajo al capital -de subvención, incluso, al capital financieroy de descapitalización de inversiones en políticas sociales.

En gran medida, la integración social a través del trabajo ha dejado de ser, en particular entre las generaciones jóvenes, un elemento articulador del proyecto vital, aumentando el empobrecimiento incluso entre quienes poseen un empleo. El acceso a la vivienda, problemático durante el anterior período de crecimiento, se ha tornado inviable para un sector de la población, a lo que se suma la paralización de la promoción de inmuebles asequibles o de alquileres de baja renta, los casos de pérdida de vivienda por impago y la imposibilidad de acceso al alquiler libre para personas y familias sin recursos o con recursos económicos insuficientes. Esta crisis habitacional se produce mientras aumenta el parque de inmuebles desocupados propiedad de entidades financieras y otros grupos empresariales, en parte procedente de la ejecución de desalojos por desahucios.

"Rescatamos a los bancos, pero no rescatamos a las víctimas de la crisis. Esa es ahora mismo la gran asignatura pendiente que tiene la política pública de vivienda. Es decir, ¿qué hacemos con todo ese sector de la población que se ha empobrecido?" (Rafael Ibáñez, gerente de VIMCORSA. Enero de 2017).

La vivienda, bien de primera necesidad, determina el acceso a otros derechos sociales y políticos pero, como apuntan Janoschka y García-Calderón (2016), constituye un bien de cambio bajo criterios e intereses del mercado agravando, en el marco de la crisis, la brecha entre intereses de las grandes corporaciones y necesidades básicas de la población. El caso español presenta particularidades: limitado parque de viviendas sociales ${ }^{6}$, encarecimiento de rentas, estímulos a la propiedad y expansión de una oferta inmobiliaria excesiva que, lejos de abaratar el acceso, lo encarece (García-Pérez y Janoschka, 2016).

Del Romero (2017) recurre a Esping-Andersen (1990) y distingue tres grandes modelos de políticas de vivienda: socialdemócrata, corporativista y liberal. En el primero, característico de países escandinavos, el acceso a la vivienda es un derecho universal. El modelo corporativista, aunque apoya al sector privado y la vivienda libre, facilita vivienda a las clases populares y familias en riesgo de exclusión social, caso de Holanda

6. En España, solo un 1,1\% del total residencial es vivienda social, porcentaje europeo más bajo tras Grecia. "Derechos desalojados. El derecho a la vivienda y los desalojos hipotecarios en España". Amnistía Internacional España. 2015. 
o Alemania. Por último, el modelo liberal, extendido en EE.UU. o Nueva Zelanda, extiende la liberalización, interviniendo el Estado, solo en casos extremos, para facilitar parcialmente alquiler social entre los sectores más desfavorecidos. En el Estado Español se habría generado, sobre todo en las dos últimas décadas, un marco desregulado que reduce el papel público a promover una insuficiente cantidad de vivienda para sectores en riesgo de exclusión social, modelo más próximo a propuestas neoliberales que a tradiciones comprometidas con el Estado de Bienestar. ${ }^{7}$ De hecho, este modelo ha actuado más como mecanismo de incentivación de los sectores financiero e inmobiliario que como estrategia social redistributiva (García-Calderón y Abellán, 2016). Como consecuencia, ha aumentado la población que, desempleada y sin recursos, se ve afectada por la exclusión residencial.

\section{CRISIS HABITACIONAL EN LA CIUDAD DE CÓRDOBA}

La crisis habitacional se agudiza en Córdoba, donde la tasa de población en riesgo de pobreza, la más alta de las capitales españolas, asciende al $37,2 \%{ }^{8}$ y donde la tasa de paro registrado llegó a superar, entre 2011 y 2015, el 30\%. ${ }^{9}$ A los precios del alquiler libre y a las dificultades del crédito hipotecario, se unen la escasez de alquiler social, la pobreza energética y los casos de hacinamiento de varias unidades y generaciones de una misma familia extensa.

AVRA (Agencia de Vivienda y Rehabilitación de Andalucía) ${ }^{10}$ había promovido en los años ochenta del pasado siglo unos 8.000 pisos, algo más de la mitad para alquiler y el resto de compra-venta o acceso diferido, en barrios con importantes bolsas de exclusión (Moreras, Palmeras y Polígono Guadalquivir), en algunos casos para sustituir asentamientos chabolistas. En la práctica, han generado espacios segregados, resultado de un modelo recurrente en Andalucía entre los años sesenta y ochenta, que concentra y aísla a estos grupos de población: los pobres son tratados como un problema marginal a la vida normal de la ciudad. Otras promociones de AVRA, proyectadas hace una década y aún no concluidas, están destinadas a personas con bajos ingresos. ${ }^{11}$

7. Documento "Diagnóstico del 'cambio'. Valencia", presentado por el investigador Luis del Romero en Seminario I+D+i "PROTO_LOCAL. De la Protesta a la Propuesta. Ayuntamientos 'del cambio', políticas urbanas y movimientos sociales”. Universidad Autónoma de Madrid. Febrero de 2017.

8. Informe "La pobreza en España pueblo a pueblo". AIS Group en base a fuentes del INE. Diciembre de 2016.

9. Expansión. Datos del Ministerio de Empleo y Seguridad Social, 2016. En 2012 la tasa de paro registrado ascendió al 30,87\%, a un 33,75\% de desempleo según la Encuesta de Población Activa. Por otra parte, el Informe Urban Audit (Instituto Nacional de Estadística, 2017) ha estimado una tasa de desempleo en la ciudad de Córdoba, en 2014, último año calculado, del 38,27\%.

10. Antes EPSA, empresa pública dependiente de la Junta de Andalucía.

11. Fuente: información obtenida de la gerencia de VIMCORSA, Viviendas Municipales de Córdoba S.A. 
La empresa municipal VIMCORSA cuenta con parque de viviendas en alquiler, alrededor de un millar, sobre todo para casos de urgencia habitacional. Son promociones en origen destinadas a un grupo de población que, aun con limitaciones económicas, posee ingresos estables. El principal problema es que acumula unas 5.000 solicitudes y, ante la falta de inmuebles, las adjudicaciones son mínimas. ${ }^{12}$ En cuanto a alquiler social de emergencia, la última lista, publicada en 2015, incluye menos de la mitad de solicitudes lo que informa del desfase entre demanda y oferta. ${ }^{13}$ Además, para poder solicitar una de las últimas viviendas construidas, los ingresos familiares deben encuadrarse entre 1 y 5,5 veces el IPREM ${ }^{14}$; o sea, entre 9.000 y 58.000 euros anuales, lo que excluye a los sectores más empobrecidos.

El área municipal de Servicios Sociales puso en marcha, en septiembre de 2015, la Oficina Municipal en Defensa de la Vivienda (OMDV) que, con precedentes en Madrid o Barcelona ${ }^{15}$, prioriza la emergencia habitacional: riesgo de desahucio, hacinamiento extremo o falta de recursos para vivienda y suministros básicos. A la conclusión del trabajo de campo, había 510 expedientes y, de 307 cerrados en el primer año, 186 habían concluido positivamente. La OMDV proporciona también ayudas para alquiler privado: a fines de 2016 había 357 solicitudes, siendo admitidas 101, muchas de ellas de familias monoparentales encabezadas por mujeres ${ }^{16}$.

El informe "Un año en pro del derecho a la vivienda digna", emitido en octubre de 2016 por la OMDV, señala como problemas de mayor gravedad la falta de recursos para el pago de un alquiler $(36,27 \%)$, el hacinamiento con familiares u otras personas $(29,02 \%)$, los realojos irregulares en inmuebles de entidades financieras (19,80\%), y el impago de hipotecas anteriores al estallido de la burbuja inmobiliaria (14,90\%).

Según los últimos datos del INE, de 2011, hay en Córdoba unos 18.000 pisos desocupados ${ }^{17}$, un $11,5 \%$ del total, y según la OMDV alrededor de 10.000 podrían pertenecer a unas entidades financieras que, en los últimos meses de 2016, habían cedido poco más de

\section{Ibídem.}

13. VIMCORSA.http://vimcorsa.com/wp-content/uploads/2015/08/Listado\%20ayudas\%20alquiler\%20 definitivo orden\%20num solicitud.pdf. Fecha de Consulta: 7/I/2017.

14. Indicador Público de Renta de Efectos Múltiples (IPREM). Índice de referencia para la concesión de determinadas ayudas sociales que sustituye desde 2004 al Salario Mínimo Interprofesional.

15. También el Programa Andaluz en Defensa de la Vivienda, impulsado en 2012, prevé oficinas provinciales coordinadas con las administraciones locales para la prevención, intermediación y protección en materia de contratación hipotecaria, desahucios, etc.

16. Datos facilitados por la Oficina Municipal en Defensa de la Vivienda (OMDV).

17. Las mismas cifras fueron expuestas por Alba Doblas, cuarta teniente de alcalde del Ayuntamiento de Córdoba, delegada de Vivienda y presidenta de VIMCORSA, en Diario Córdoba, el 13 de agosto de 2015. 
medio centenar a casos de crisis habitacional extrema. ${ }^{18}$

Entre 2008 y 2014 se produjeron en la provincia 4.142 lanzamientos. Aunque los datos locales no están desagregados, se estima que entre 2.000 y 2.500 debieron ejecutarse en Córdoba ciudad. ${ }^{19}$

\section{Cuadro 1.- Lanzamientos recibidos en la provincia de Córdoba. \\ Fuente: Oficina Municipal en Defensa de la Vivienda}

\begin{tabular}{|c|c|}
\hline Año & Número de lanzamientos \\
\hline 2008 & 226 \\
\hline 2009 & 263 \\
\hline 2010 & 433 \\
\hline 2011 & 599 \\
\hline 2012 & 971 \\
\hline 2013 & 903 \\
\hline 2014 & 747 \\
\hline
\end{tabular}

En las elecciones municipales de 2015, vivienda y desahucios estuvieron presentes en los programas de los actuales grupos municipales que apoyan, de una u otra forma, al gobierno local. ${ }^{20}$ La creación de una oficina por el derecho a la vivienda, la gestión del parque de viviendas vacías y el asesoramiento ante el impago de obligaciones hipotecarias, fueron puntos comunes. IU y Ganemos incluían, además, el fomento del alquiler social y de cooperativas sociales en propiedad de uso, la oposición a los desahucios, la garantía de

18. Según responsables de la OMDV (Oficina Municipal de Defensa de la Vivienda), de las 510 familias atendidas con expediente abierto en 2016 solo se habían podido asignar 17 viviendas en régimen de alquiler social.

19. Documento La Oficina Municipal en Defensa de la Vivienda. Avance Programación. Sin Fecha. Documento no publicado.

20. El gobierno local de Córdoba está constituido, desde junio de 2015, por una coalición formada por PSOE-A e Izquierda Unida, apoyada desde fuera, de manera crítica, por Ganemos. 
suministros básicos y, en el caso de Ganemos, "la despenalización de las ocupaciones de viviendas vacías de grandes propietarios y fondos de inversión por familias sin alternativa habitacional"21. El Acuerdo de gobierno, suscrito por PSOE-A, Ganemos Córdoba e IU, especifica en su primer apartado:

"Es necesario que el Ayuntamiento de Córdoba lidere el rescate de los ciudadanos que están sufriendo lo peor de la crisis poniendo todos los medios y recursos municipales para luchar contra los desahucios de personas sin alternativa habitacional".22

El Acuerdo añade garantía de suministros básicos de agua y electricidad, declaración de Córdoba como "ciudad por la vivienda digna y contra los desahucios", bolsa de alquiler social de inmuebles vacíos negociada con entidades financieras, y convenios con autoridades judiciales para evitar desahucios sin alternativa habitacional sin previa comunicación a los servicios sociales municipales.

\section{LAS UNIDADES FAMILIARES ESTUDIADAS}

\subsection{Situaciones con respecto a los inmuebles objeto de realojo}

Las unidades familiares de la muestra pueden ser agrupadas:

- Con proceso judicial abierto: pendientes de juicio, de orden de lanzamiento o con fecha de desalojo. Situación de 37 familias, 33 pendientes de juicio o con proceso judicial abierto y 4 con fecha de lanzamiento. Suponen el 61,67\% de la muestra.

- Que han conseguido alquiler social o que se encontraban en negociación. Suman 10 familias, un $16,67 \%$ de la muestra.

- Que han negociado o se encontraban negociando la dación en pago y un alquiler social en la que fue su propia vivienda. Situación de 12 familias, un 20,00\% de la muestra.

Estas situaciones incluyen una persona en piso compartido en régimen de alquiler social, gestionado por la OMDV como parte del Fondo Social, y dos familias en situación de hacinamiento.

21. Programa Municipal del PSOE-A, Córdoba. 75 Propuestas del Programa Marco Municipal del PSOE. 2015. Programa de Gobierno de Izquierda Unida para Córdoba. 2015. Programa electoral Elecciones municipales 2015. Ganar Córdoba para las personas. Ganemos Córdoba. 2015.

22. Documento Propuesta de Acuerdo de principios, objetivos y medidas programáticas para el Gobierno Municipal de Córdoba 2015-2019. Apartado A, Rescate ciudadano y política social. 2015. 
Cuadro 2.- Situaciones de las unidades familiares de la muestra con respecto a la vivienda habitada. Fuente: trabajo de campo

\begin{tabular}{|l|c|c|}
\hline \multicolumn{2}{|l|}{ Situación de unidad familiar / vivienda } & $\begin{array}{c}\text { de unidades } \\
\text { familiares }\end{array}$ \\
\hline Realojada con proceso judicial abierto & 33 & $55,00 \%$ \\
\hline Realojada con fecha de desalojo & 4 & $6,67 \%$ \\
\hline $\begin{array}{l}\text { Realojada en alquiler social (o en } \\
\text { negociación) }\end{array}$ & 10 & $16,67 \%$ \\
\hline $\begin{array}{l}\text { Dación en pago y alquiler social (o en } \\
\text { negociación) }\end{array}$ & 12 & $20,00 \%$ \\
\hline $\begin{array}{l}\text { Otras situaciones (en vivienda de } \\
\text { familiares) }\end{array}$ & 1 & $1,67 \%$ \\
\hline TOTAL & $\mathbf{6 0}$ & $100,00 \%$ \\
\hline
\end{tabular}

Las entidades propietarias de los inmuebles son: Banco Santander (17), Banco Popular (11), Cajasur (11), La Caixa (10), Caja Rural (4), Unicaja (2), Bankia (1) y BBVA (1). Un caso particular incluye un fondo de inversión con sede en Luxemburgo y, otro, una orden religiosa. Otro caso es una familia en hacinamiento con otros familiares. El cruce de entidades y familias realojadas, distinguiendo casos de dación en pago y alquiler social y otro tipo de alquiler social, negociado o en proceso de negociación, arroja los siguientes resultados: 
Cuadro 3.- Entidades financieras y casos de dación en pago y alquiler social o de realojo y alquiler social.Fuente: trabajo de campo

\begin{tabular}{|l|c|c|}
\hline Entidad propietaria & $\begin{array}{r}\text { Dación en pago y } \\
\text { alquiler social }\end{array}$ & $\begin{array}{c}\text { Realojo y alquiler } \\
\text { social }\end{array}$ \\
\hline Banco Santander & 1 & 1 \\
\hline Banco Popular & 3 & 0 \\
\hline Cajasur & 4 & 3 \\
\hline La Caixa & 2 & 4 \\
\hline Unicaja & 1 & 0 \\
\hline Caja Rural & 1 & 1 \\
\hline BBVA & 0 & 0 \\
\hline Bankia & 0 & 1 \\
\hline Otras entidades / situaciones (compartido) & 0 & $\mathbf{1 0}$ \\
\hline TOTAL & $\mathbf{1 2}$ & 0 \\
\hline
\end{tabular}

4.2. Parejas jóvenes con menores y mujeres jóvenes al frente de familias monoparentales. Bajos niveles de estudios y escasa cualificación profesional

Las 60 unidades familiares estudiadas suman 165 personas, entre ellas 64 menores de 18 años: 40 hombres y 24 mujeres. 21 tienen menos de 4 años (16 niños y 5 niñas), 31 tienen entre 4 y 12 años (19 niños y 12 niñas) y 12 entre 13 y 17 años (5 hombres y 7 mujeres). 52 niños y niñas son menores de 13 años.

De las 101 personas adultas (47 hombres y 54 mujeres), 40 tienen entre 18 y 30 años (19 
hombres y 21 mujeres), 45 entre 31 y 50 ( 22 hombres y 23 mujeres) y 16 entre 51 y 70 años (6 hombres y 10 mujeres). La mayor concentración de adultos se registra entre 20 y 45 años. El número de mujeres adultas con respecto al de hombres refleja varias familias monoparentales encabezadas por mujeres: 1 con 3 hijos/as, 2 con 2 hijos/as y 3 con 1 hijo/a.

\section{Cuadro 4.- Datos de la muestra por sexos y grupos de edad} Fuente: trabajo de campo

\begin{tabular}{|c|c|c|c|}
\hline Grupo de edad & Hombres & Mujeres & TOTAL \\
\hline $0-3$ años & 16 & 5 & 21 \\
\hline $4-12$ años & 19 & 12 & 31 \\
\hline $13-17$ años & 5 & 7 & 12 \\
\hline Total menores & $\mathbf{4 0}$ & $\mathbf{2 4}$ & $\mathbf{6 4}$ \\
\hline $18-30$ años & 19 & 21 & 40 \\
\hline $31-50$ años & 22 & 23 & 45 \\
\hline $51-70$ años & 6 & 10 & 16 \\
\hline Total adultas & $\mathbf{4 7}$ & $\mathbf{5 4}$ & $\mathbf{1 0 1}$ \\
\hline
\end{tabular}

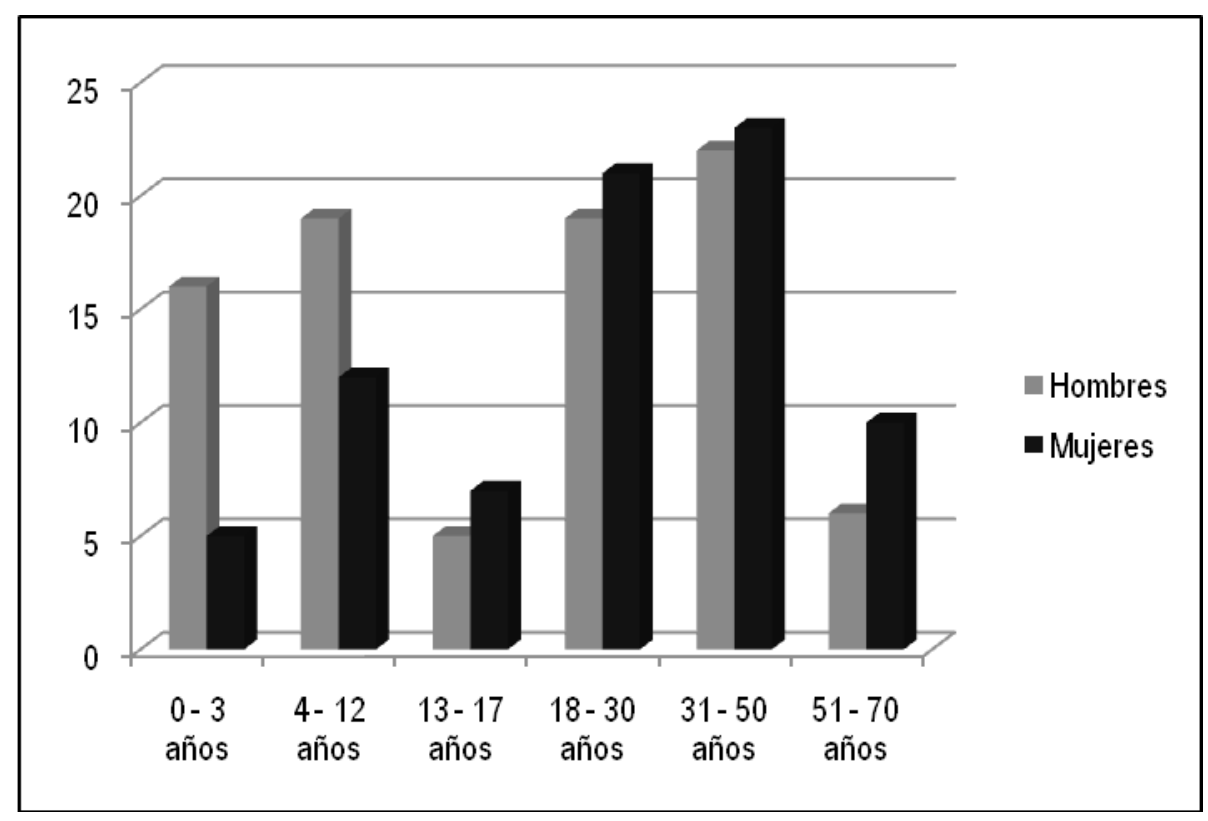


Los niveles de estudios entre los 106 mayores de 16 años presentan que 41 personas no tienen estudios o tienen estudios primarios incompletos, 47 tienen estudios primarios y 18 estudios secundarios y/o formación profesional.

Cuadro 5.- Datos de la muestra por niveles de estudios. Fuente: trabajo de campo

\begin{tabular}{|l|c|c|}
\hline Nivel de estudios & $\begin{array}{c}\text { Número de personas } \\
\text { (mayores } \mathbf{1 6} \text { años) }\end{array}$ & $\%$ \\
\hline $\begin{array}{l}\text { Sin estudios, Primarios } \\
\text { incompletos }\end{array}$ & 41 & $38,68 \%$ \\
\hline Estudios Primarios & 47 & $44,34 \%$ \\
\hline Estudios Secundarios, F.P. & 18 & $16,98 \%$ \\
\hline TOTAL & $\mathbf{1 0 6}$ & $\mathbf{1 0 0 , 0 0 \%}$ \\
\hline
\end{tabular}

\subsection{Desempleo de larga duración, precariedad laboral, empobrecimiento y exclusión}

De 104 personas en edad de trabajar 98 están desempleadas: un 94,23\% de la muestra. 13 de ellas, todas mujeres, trabajan como limpiadoras en situación irregular, 4 en recogida y venta de chatarra, 4 como temporeros agrícolas, 6 en otras faenas informales y solo 6 , un $5,77 \%$ de la muestra, declaran trabajar con contrato y Seguridad Social.

Cuadro 6.- Datos de la muestra sobre ocupaciones laborales.

Fuente: trabajo de campo

\begin{tabular}{|c|c|c|}
\hline $\begin{array}{c}\text { En desempleo: } 98 \text { personas de } 104(94,23 \%) \\
\text { Tipo de ocupación }\end{array}$ & $\begin{array}{c}\mathrm{N}^{\circ} \mathrm{de} \\
\text { personas }\end{array}$ & $\%$ \\
\hline Desempleo (sin ninguna actividad) & 69 & $66,35 \%$ \\
\hline Limpieza (economía informal) & 13 & $12,50 \%$ \\
\hline Chatarra (economía informal) & 3 & $2,88 \%$ \\
\hline Peón agrícola (economía informal) & 4 & $3,85 \%$ \\
\hline Otras actividades informales & 9 & $8,65 \%$ \\
\hline Empleo regular (contrato y S.S.) & 6 & $5,77 \%$ \\
\hline TOTAL & 104 & $100,00 \%$ \\
\hline
\end{tabular}


Algunas de estas personas se consideran "trabajando" y no desempleadas, aun realizando faenas en la economía informal. Con independencia de que, en efecto, trabajan, expresan con naturalidad un concepto de "trabajo" ajeno al empleo regularizado, estable y con derechos.

La mayoría de familias están encabezadas por personas desempleadas de larga duración. De ellas, 14 declaran no contar con ingresos y recibir apoyo de familiares, ONGs o entidades religiosas. 11 unidades familiares perciben subsidios por desempleo, 4 salarios sociales y 12 distintas pensiones de cuantías reducidas. Al margen de estas ocupaciones y subsidios, la generalidad de familias vive en situación de pobreza o riesgo de exclusión: 14 sin ingresos (23,33\%), 8 con ingresos mensuales inferiores a 300 euros $(13,33 \%)$ y 22 con ingresos de entre 300 y 500 euros (36,67\%). 10 familias disponen de ingresos mensuales de entre 500 y 800 euros (16,67\%) y sólo 6 entre 800 y 1000 euros. ${ }^{23}$

\section{Cuadro 7.- Datos de la muestra sobre ingresos familiares medios mensuales. Fuente: trabajo de campo}

\begin{tabular}{|l|c|c|}
\hline \multicolumn{1}{|c|}{ Ingresos medios mensuales } & $\mathbf{N}^{\mathbf{0}}$ unidades familiares & $\%$ \\
\hline Sin ingresos & 14 & $23,33 \%$ \\
\hline Menos de 300 euros & 8 & $13,33 \%$ \\
\hline $300-500$ euros & 22 & $36,67 \%$ \\
\hline $500-800$ euros & 10 & $16,67 \%$ \\
\hline $800-1000$ euros & 6 & $10,00 \%$ \\
\hline TOTAL & $\mathbf{6 0}$ & $100,00 \%$ \\
\hline
\end{tabular}

Las familias se distribuyen por barrios de la expansión periférica de la segunda mitad del siglo XX (barrios obreros) y por zonas populosas del casco histórico.

23. Referencia: Encuesta de Condiciones de Vida. Instituto Nacional de Estadística. Riesgo de pobreza: ingresos inferiores a 8.011 euros persona/año. Riesgo de exclusión: ingresos inferiores a 663,3 euros hogar/mes. Indicador AROPE (At Risk of Poverty). 


\section{Cuadro 8.- Distribución de la muestra por zonas según GAYAM. Fuente: trabajo de campo}

\begin{tabular}{|l|c|}
\hline \multicolumn{1}{|c|}{$\begin{array}{c}\text { Zona o barrio GAYAM } \\
\text { de referencia }\end{array}$} & No de unidades familiares \\
\hline Sur & 20 \\
\hline Fátima & 13 \\
\hline Miralbaida & 10 \\
\hline Santuario & 8 \\
\hline Axerquía & 7 \\
\hline $\begin{array}{l}\text { Afectadas por hacinamiento(1 Fuensanta, } \\
\text { 1 Sector Sur) }\end{array}$ & 2 \\
\hline TOTAL & $\mathbf{6 0}$ \\
\hline
\end{tabular}

\section{EXPERIENCIAS DE LAS FAMILIAS REALOJADAS}

"Subieron y nos pidieron los carnés. Y yo le dije a la policía: 'dice mi Estado Español que yo tengo derecho a una vivienda'. $Y$ el agente va y me dice: 'si puede usted comprarla"'

Las familias han visto agravada su situación en los últimos años para satisfacer necesidades básicas y acceder a la vivienda. Pueden distinguirse dos grupos: por un lado, familias encabezadas por personas con escasa cualificación, dificultad para acceder al empleo e ingresos mínimos que ya vivían en situación de riesgo de exclusión o en la exclusión social. Son parejas jóvenes, o mujeres jóvenes, con menores. Por otro lado, familias encabezadas por personas con cualificación básica o media e integración social en base al trabajo regularizado que, al perder el empleo, no han podido pagar las cuotas hipotecarias y se han visto obligadas a negociar la dación en pago y un alquiler social en la que fue $s u$ vivienda o, en determinados casos, tras el desalojo, se han realojado, como el grupo anterior, en otro inmueble de una entidad financiera.

La gerencia de VIMCORSA constata la magnitud de estas situaciones:

"Hay verdaderos dramas que van en aumento, porque además tenemos a la población más vulnerable históricamente; y luego tenemos a muchísima población que está con ingresos cero, porque han caído y se han empobrecido, 
y tienen menos habilidades para manejarse en una situación crítica" (Rafael Ibáñez, gerente de VIMCORSA. Febrero de 2017).

\section{1. "Entrar a vivir en la casa de un banco": "Hay que estar muy convencido"}

"Entrar a vivir en la casa de un banco" puede implicar delito de "usurpación", riesgo solo comprensible si se atiende a la extrema necesidad que lo provoca. Los colectivos de apoyo insisten en que quienes opten por ello deben estar "muy convencidos". Son importantes los apoyos entre la vecindad, el asesoramiento, la información sobre el inmueble y su situación legal, sobre la entidad propietaria y su respuesta habitual. También, cuando proceda, es conveniente reunir documentos que acrediten la situación familiar y su trayectoria antes del realojo, así como procurarse asistencia para la negociación y ante la intervención judicial. 15M Stop Desahucios Córdoba asesora sobre propiedad de los inmuebles, actuación en las primeras 72 horas y ante la intervención policial, trámites técnicos, defensa ante demandas de la propiedad, negociación, apoyo emocional y acciones de presión ante instancias políticas y bancarias.

El acceso al inmueble debe ser discreto con el objetivo de dilatar la intervención policial o de la propiedad. Se dan, no obstante, casos de realojo al margen de las plataformas, a veces con ayuda de mediadores que facilitan el acceso al inmueble a cambio de ciertos pagos. Son personas que se buscan la vida prestando servicios que consisten en detectar inmuebles vacíos de bancos, abrir la puerta, enganchar la luz, e incluso recomendar acudir "a los de Stop Desahucios".

"El matrimonio que estaba aquí antes, pidió 40 euros por un piso. Y nosotros, como no teníamos ya dinero y estábamos viviendo sin alquiler, que estábamos viviendo prácticamente en la calle, que no teníamos ya donde meternos, pues dijimos 'mira vamos a pagarle 40 euros y nos metemos'. Y así fue" (Victoria. Diciembre de 2016).

"Esta casa, nos dijeron que era $350 €$ por abrirnos la puerta. Pero, mira, estábamos muy malamente y digo: 'mira, poco a poco..."' (Eduardo. Diciembre de 2016).

Otros informantes refieren apoyos sin petición de dinero:

"Este hombre es amigo de toda la vida de su padre, que en paz descanse, y le dijimos que queríamos buscar un piso pero, como no sabíamos cómo iba esto, me dijo: 'mira, esto era para un sobrino mío pero no quiere, si tú quieres...' Y se la dio" (Informante: Pepa. Diciembre de 2016) 
"Pues me abrió el piso un amigo mío que entró por la ventana y me abrió el piso por dentro. La vecina de abajo dejó que subiera para arriba por la ventana... ¡Para haberse matado!” (Informante: Luisa. Enero de 2017)

O resolvieron el acceso por sus propios medios:

"Estuve buscando pisos de bancos por internet y encontré... un montón de páginas. Yo me vine a esta vivienda, tenían puesto el cartel ahí, en la ventana, de una empresa que trabaja para La Caixa y así la encontré, y decidí meterme en una y nos metimos. Pues vine yo con el cerrajero, le dije al cerrajero que yo era la chica que vende los pisos, me hice pasar por ella. Me abrió la puerta, le pagué al cerrajero y ya me metî" (Rosalía. Noviembre de 2016).

Aunque, con frecuencia, ante las autoridades, "la puerta estaba abierta":

"Yo me enteré de esta casa por internet (...) Y me dijeron que estaba abierta. No estaba abierta del todo, pero la puerta estaba reventadilla: le hice así y me metí aquí" (Informante: Pepe. Diciembre de 2016).

El acceso debe ocasionar los mínimos daños posibles, procurando que la policía o la propiedad no acudan hasta pasados varios días. Las plataformas ciudadanas aconsejan no permitir a los agentes de policía el acceso al inmueble sin una orden judicial.

\subsection{Acondicionar los inmuebles y conseguir suministros básicos. El miedo}

Los inmuebles, cerrados y en ocasiones en estado de abandono, carecen de suministros y presentan condiciones de insalubridad. Durante los primeros días, los informantes refieren "miedo":

"Las tuberías, los codillos... estaban quitados. Y tuvimos que pedir prestado y comprar todas las tuberías. Haciendo las heces en un cubo estuvimos meses, y bajando el cubo a la una de la mañana cuando estaba todo el mundo acostado. A lo primero te da mucho miedo cuando te metes en una vivienda, te da un miedo acojonado, pero ya se te quita. Ya, dices: 'que venga el que quiera'. Ahora estás sin agua, ahora estás sin luz, ahora no tienes para comer... Horrible" (Rafi. Noviembre de 2016).

"La casa estaba completamente vacía (...) Antes de meternos ya nos pusimos en contacto con ellos [Stop Desahucios] y teníamos miedo, la verdad. Con miedo estuvimos unos días" (Rosa. Diciembre de 2016).

"Me emborraché... Porque si no... ¡No era capaz! Era... o me quito la vida, que me la iba a quitar, pero del tirón que me la quitaba, o buscar la primera puerta que encontrara” (Informante: Pepe. Diciembre de 2016). 
Para demostrar que la vivienda está siendo efectivamente habitada es preciso introducir enseres personales:

"A los tres días ya teníamos allí cosas. Un vecino nos dijo: 'en el momento que metáis muebles no os pueden echar. Que vean que habéis limpiado; meter aunque sea una tele, que os vean que tenéis luz con la tele y todo. Yo metí los colchones sin somier, y la tele en un banquito de madera" (Mati. Diciembre de 2016).

La luz suele engancharse de manera irregular; también se puede solicitar un nuevo contrato a la empresa eléctrica si la vivienda está al corriente del pago, algo infrecuente.

"No tenemos luz todavía [llevan un mes sin luz]. Por la noche lo que tengo es una alargadera que va a casa de mi madre y enciendo la lamparita. Ya está, eso es lo que tengo. Y luego, para dormir al niño me pongo la linterna del móvil y ya está" (Rosa. Diciembre de 2016).

Servicios Sociales del ayuntamiento ha negociado con ENDESA, principal operadora en Córdoba, un suministro mínimo a familias sin recursos económicos para que no se interrumpa el suministro a nadie que se dirija a los servicios sociales mientras se habilitan soluciones alternativas. El abastecimiento de agua es, desde comienzos de 2016, también por intervención municipal, accesible acreditando el empadronamiento -o la solicitud- en cualquier domicilio.

Además de asegurar suministros de luz y agua, el adecentamiento de las viviendas es una tarea esencial. Las familias entran en inmuebles con obras inacabadas, goteras y humedades, incluso con basuras, insectos y ratas.

"Yo cuando entré y vi esto... yo no paraba de llorar. Hasta que no lo limpiamos bien un poco y quitamos los escombros, esto era un caos" (Milagros. Diciembre de 2016).

"La casa era una porquería cómo estaba todo. Que de aquí saqué en sacos de basura de litronas, de porros, de papelitos... de todo. Y la cocina cómo estaba, que las lombrices corrían por la pared. Esto era... Y nosotros lo limpiamos todo (...) El baño de arriba no se utiliza porque cuando abro la ducha de arriba se me inunda la cocina. La lavadora tengo que poner la manguera en una piscina, porque si no, se me inunda la cocina. Y ese váter, cuando entramos, estaba atascado de mierda, todo lleno de meados... era una porquería..." (Rosa. Diciembre de 2016).

Varios informantes refieren haber arreglado la vivienda con donaciones de vecinos y amigos o de asociaciones. Se han podido observar inmuebles, antes muy deteriorados, 
limpiados a conciencia, pintados, con reparaciones y con enseres que proceden de donaciones, de segunda mano o "de la chatarra".

"La casa estaba, vamos, comida de mierda, que ahí no se ha limpiado vamos, en seis años. Ni grifos ni había nada. Los grifos me los ha dado un amigo de mi padre y mi padre me los ha colocado. Las vecinas me decían: 'lo que necesites..."' (Mari Ángeles. Noviembre de 2016).

Mientras las familias se acomodan van ampliando relaciones con otras personas del entorno o con asociaciones vecinales, recabando apoyo social y visibilizando los realojos como acciones normalizadas.

"Con los vecinos del barrio nos llevamos muy bien (...) Y venía aquí la gente a decirnos que 'enhorabuena' por nuestro comportamiento; y, nada, que siguiéramos así” (Ana. Noviembre de 2016).

"Esta casa era de unos vecinos que no pudieron pagar y le quitaron el piso. Y me enteré yo que se iban a meter aquí otras personas, y me dijeron los mismos vecinos que antes que se metan otras personas, pues... 'métete tú, que sabemos que te hace falta y sabemos cuál es tu situación'. Y así lo hice. Me eché para adelante y me metí... Los vecinos saben que estoy aquí de ocupa, lo saben todos. El primer día, el presidente de la comunidad me pilló con la puerta abierta y dijo 'es que yo tengo que llamar al administrador, a la policía'. Claro, porque él no sabía que era yo la que me había metido. Él vio al chaval éste, el que me abrió la puerta y que estaba poniendo la cerradura. Y digo: 'que he sido yo la que me he metido' $Y$, al final, ni han llamado a nadie ni nada" (Luisa. Enero de 2017).

\subsection{Intervención policial y de la propiedad. Negociación y proceso judicial}

Las relaciones con la policía y la entidad propietaria registran casuísticas muy variadas. Antes o después la policía acude a identificar a las personas realojadas y la propiedad interviene en defensa de sus intereses. Esta última puede favorecer un proceso de negociación y acuerdo promoviendo un contrato de alquiler social con la familia realojada, algo que ocurre en muy pocos casos o, lo más frecuente, interponer demandas judiciales por usurpación con petición de desalojo.

"Vinieron dos coches de policía y dos de inspectores. Nos cogieron los datos y una pareja de municipales nos dijeron que nos teníamos que salir, y yo le dije que cómo nos íbamos a salir, que teníamos niños... Y la otra pareja de municipales le dijeron que no nos podíamos salir porque ya estábamos alojados, que teníamos niños y teníamos ya cosas metidas en la vivienda. Yo les dije: 'vamos, que podéis pasar que yo vivo sola con mis niños'; y me 
dijeron: 'no, ya hemos hablado con tu vecina y nos ha dicho que tú vives sola con tus niños. O sea que no hace falta que veamos la casa porque por mi parte os digo que no os salgáis. Y nos dejaron al final porque los inspectores dijeron también que no nos saliéramos" (Teo. Enero de 2017).

"No quería abrir pero cuando he escuchado 'Mire, tenemos que abrir la puerta', que la iban a abrir, con los cerrajeros y todo... Y le dije a Rafa que la abriera porque nos tiran la puerta abajo, y ahí me han dicho que me saliera y que me saliera: 'Que te sales y punto y que me da igual lo que me digas'. Nos han mandado a firmar unos documentos pero le he dicho yo que no firmaba. $Y$ me lo ha leído el hombre y nos ha denunciado: como desacato a la autoridad, como que no hemos salido. Después, que se aplaza hasta el día diecisiete que es el juicio... A ver, estoy más tranquila porque se fueron, pero yo estoy fatal, es que ya está aquí y como me ha dicho la mujer eso, que me echan, que me echan, que me echan..." (Mati. Diciembre de 2016).

"Yo entré un sábado y la policía vino esa noche. Pero, claro, la policía no entró en la casa ni nada. Y el lunes, a los dos días, me vino el banco ya. Yo le dije a la policía que llevaba una semana, me tomó los datos y vino el del banco el lunes, y me dijeron: 'chiquilla, ¿cómo te has metido aquí como está la casa?'. Y yo le dije: 'pasad si queréis'. El del banco dijo: 'si huele a limpio, si nosotros sabemos cómo estaba la casa"' (Paula. Noviembre de 2016).

Las plataformas recomiendan intentar por todos los medios la negociación y evitar un proceso judicial pues, sobre todo las familias realojadas en las que fueron sus propias viviendas, pueden estar en mejor posición para la dación en pago y un alquiler social. En realidad, son los bancos -o inmobiliarias o empresas intermediarias- quienes optan por la negociación o por denuncias que pueden conllevar multa y desalojo. También influyen en el proceso el turno de oficio, la habilidad negociadora de las familias o sus representantes y, en última instancia, la decisión judicial.

La negociación, cuando se produce, entraña dificultades y la representación de las familias recae en técnicos de la OMDV, en miembros de Stop Desahucios o en la coordinación de ambos. Existen dos opciones: recurrir al Fondo Social de la Vivienda, donde las entidades propietarias ceden un número de inmuebles, muy escaso, para su alquiler social, o celebrar encuentros entre entidades y negociadores de las familias que pueden ir acompañadas de acciones de presión.

El marco, en cualquier caso, es definido por las entidades propietarias ya que, al carecer de obligación normativa, permitir la permanencia en el inmueble y el alquiler social es, en principio, discrecional. De hecho, cada entidad tiene sus propias estrategias de 
negociación partiendo por lo general de la negativa al acuerdo; incluso hay bancos que actúan a través de empresas intermediarias para convertir pasivos en activos financieros, delegando en ellas las negociaciones.

Negociadores de Stop Desahucios informan que algunos bancos, aunque empiezan a responder positivamente, lo hacen de manera muy lenta. Parten de la consideración del realojo como delito y, probablemente, del temor a un efecto llamada; además, las entidades son conscientes de las dificultades para rentabilizar determinados inmuebles desocupados y de la impopularidad de algunas de sus actuaciones. Pero la lentitud de las negociaciones contrasta con la emergencia de las familias.

"el alquiler social con los realojados se puede conseguir pero con mucha lucha, porque los bancos están reacios. Ellos parten de que eso es un delito, tienen a los jueces a su lado también, que es fundamental, y únicamente cuentas con su buena voluntad, ya está. Realmente es eso, porque ellos ahí lo tienen todo de su parte. Hombre, si tienen hijos a cargo es un aliciente que se utiliza para luchar y parar lanzamientos". (Fermín, negociador de Stop Desahucios. Noviembre de 2016).

Sobre el cumplimiento por parte de las entidades del Código de Buenas Prácticas, regulado en el Real Decreto Ley 6/2012, de 9 de marzo, de medidas urgentes de protección de deudores hipotecarios sin recursos ${ }^{24}$, los negociadores de Stop Desahucios refieren "intransigencia", "endurecimiento" y "aplicación restrictiva de la Ley"; de ahí las acciones de presión y que responsabilicen de esta situación a la parte propietaria, a su vez "apoyada por el gobierno":

"Si los bancos lo hubieran asumido [el derecho a la vivienda] habrían ofrecido las viviendas que tienen vacías a los municipios, los ayuntamientos, a la Junta... para que tuvieran un parque de viviendas para alquileres sociales. Los bancos no quieren asumir ese tema, han tenido siempre el respaldo del gobierno, que les ha respaldado en todo momento y le han apoyado en todas las medidas. Y ha habido algunos retoques legislativos, pero han sido mínimos. Y más bien forzados por la pelea que hemos tenido en este país las plataformas. Pero ellos, en el fondo, no quieren realmente dar ese paso y no quieren reconocerlo" (Javier, miembro de Stop Desahucios. Diciembre de 2016).

El proceso judicial de un realojo puede discurrir por la vía penal o por vía civil. Es la entidad propietaria quien opta por uno u otro tipo de demanda, siendo frecuente que los realojos individuales vayan por ambas vías, mientras las ocupaciones colectivas lo hacen por vía penal. Ésta juzga un delito de usurpación, con penas de 3 a 6 meses de

24. BOE Núm. 60, de 10 de marzo de 2012. 
días/multa, pudiendo conllevar en caso de impago o insolvencia privación de libertad de un día por cada dos impagados o condena de prestación de servicios a la comunidad. El inmueble objeto del realojo debe estar sin habitar pues, en caso contrario, conllevaría mayor gravedad y pena; además, que el inmueble lleve un largo período deshabitado puede esgrimirse frente a una medida cautelar de desalojo.

En el proceso de negociación y, en su caso, ante el juzgado, las plataformas recomiendan que se exprese que el realojo en el inmueble objeto del litigio obedece a la "extrema necesidad" y la "ausencia de alternativas"; y que los realojados dejen clara su no pretensión de permanencia indefinida y su aceptación de cualquier otra vivienda en régimen de alquiler social. Las defensas esgrimen esta "extrema necesidad" para cuestionar la existencia de usurpación.

"Nosotros sabemos que esto tiene un dueño, y sabemos lo que nos puede pasar. Pero nosotros no nos negamos a pagar un alquiler social. Eso ante todo: que no nos negamos. Que dentro de nuestras posibilidades, que no nos negamos; pero que no nos dejen en la calle, porque la calle es muy dura, la calle es muy dura... A mí no me importaría que me cambien de vivienda. Yo con tal de que no nos dejen en la calle..." (Pilar. Noviembre de 2016).

Nos dijo [el juez] que si sabíamos que estábamos haciendo un delito y le dijimos que delito no estábamos haciendo ninguno, que lo que estábamos es ocupando una vivienda por necesidad porque otra cosa no tenemos: o nos metemos ahí o nos vemos en mitad de la calle (Mercedes. Diciembre de 2016).

La defensa ante la vía civil es más complicada pues lo que se litiga es quién ostenta la propiedad del inmueble, algo que no admite discusión. En ambos casos, penal y civil, se pueden presentar recursos, así como escritos y peticiones de colectivos y movimientos sociales.

\subsection{Dación en pago y alquiler social en la que fue la propia vivienda}

El desahucio de la propia vivienda puede representar una de las expresiones más crueles de la dimensión antisocial de los poderes financieros, de la insensibilidad de las élites políticas y de la inhibición de gran parte de la sociedad ante el sufrimiento generado por la crisis. De ahí que el realojo sea legitimado por las plataformas civiles, por las personas afectadas y por otros sectores sociales, pudiendo además facilitar la negociación para que el proceso judicial no se cierre de manera desfavorable. No siempre es posible.

"El banco no ha querido sentarse a negociar, no han atendido llamadas...

Yo he ido dos o tres veces al Cajasur y directamente me han dicho que me tengo que reunir con el comité de negociadores, me reúno con el comité de negociadores y me dicen que me tengo que reunir con la directiva del Cajasur. 
Voy a la directiva del Cajasur y me dicen que no. Marearme porque sí. Y así me he tirado detrás de ellos, y pim pam, pim pam, para nada, para eso. De un lado a otro, de un lado a otro..." (Rafael. Diciembre de 2016).

Algunas familias refieren procesos de negociación más fluidos, incluso, en determinados casos, al amparo de cierta regulación normativa.

"Yo ganaba una media de 1.500 euros y mi mujer, pues, estaba ganando seiscientos o setecientos euros. No había para mucho, pero había para pagar la hipoteca y para poder vivir. Empezaron a cerrar inmobiliarias, empezaron a cerrar negocios, los bancos ya no daban créditos, y ahí me quedé parado... En ese momento fue cuando empiezan los problemas, cuando los gastos son los mismos pero los ingresos son menos de la mitad. Ya te empiezan a llegar las cartas del banco, te empiezan a llegar llamadas, te llama el director, te dice 'usted no paga.... Lo malo de la deuda es que si tienes que pagar seiscientos euros al mes se convierten en setecientos y pico con los intereses por impago. Entonces, no puedes pagar. $\mathrm{Y}$ al tercer mes que no pagas ya te llega una carta del banco diciendo que tienes que abonar la hipoteca completa más los intereses en el plazo de una semana. Con lo cual eso te imposibilita a todo. Lo normal es que la casa vaya a subasta, te quedas sin vivienda, $y$ al final terminas también debiéndole al banco, debiéndole una cantidad de veinte o treinta mil euros de intereses que no vas a poder pagarle en la vida. Yo lo que hice, que en ese momento salió la ley de buenas prácticas bancarias, fue la dación en pago que se dice normalmente. Y lo que hice fue que al banco se le presentó toda la documentación, porque yo no tenía ingresos suficientes. Estuvimos hablando con el banco, con el Popular. Porque la dación en pago estaba hecha para personas que fuera su primera vivienda y no pudieran pagarla, para que no se quedaran en la calle. Por ahí empezamos... Y tardó unos cuatro meses en que me dieran la dación en pago. Yo me acuerdo que me llamó el del banco y me dijo que mañana firmábamos, que necesitaba seiscientos euros para la fianza... iy yo no tenía seiscientos euros! Al final me he quedado en mi misma casa con un alquiler social de doscientos euros durante tres años y me he quedado sin hipoteca. Y no tengo deuda. Y eso es lo mejor parado que he podido salir..." (José Manuel. Enero de 2017).

Pero los procesos se dilatan en el tiempo, incluso el acuerdo llega con posterioridad al desalojo, recurriendo la familia a realojarse de manera irregular para poder negociar. La generalidad de informantes refiere desesperación por la pérdida de su casa o ante la posibilidad de que la perdieran los familiares que les habían avalado.

"Que ya no me salen lágrimas para llorar. Te lo juro, eh... Ya no me salen 
lágrimas para llorar, porque llevo siete meses que para mí se están quedando, para mí y para mi familia. Porque esto no es justo, que nos echen de las casas y ahora que no nos den vivienda. ¡Que nos tienen que dar una vivienda! Esto no es justo" (Asun. Diciembre de 2016)

\section{A MODO DE CONCLUSIÓN: DEL SUFRIMIENTO Y LA IMPOTENCIA A LA ACCIÓN COLECTIVA CON FUERTE COMPONENTE DE GÉNERO}

Primero.- Con independencia de otras ocupaciones de inmuebles que pudieran estar dándose en Córdoba, las familias estudiadas que han optado por el realojo, de manera irregular, en inmuebles propiedad de entidades financieras, lo han hecho motivadas por situaciones de extrema necesidad y ante la falta de otras alternativas, en un contexto de grave crisis habitacional que contrasta con el acaparamiento de miles de inmuebles en desuso por parte de aquellas corporaciones.

Segundo.- La vivienda constituye un espacio primordial desde el que poder abordar otras necesidades y la quiebra de esa base de seguridad genera miedo, desesperación, impotencia e interiorización de reproches desde valores muy asentados: fracaso, incapacidad para sacar a la propia familia adelante, criminalización por desobedecer o desafiar al orden establecido... La constatación del sufrimiento de las personas afectadas ha sido una constante durante la investigación y el realojo y la lucha por permanecer en la vivienda ocupada llega a ser vivida como una batalla contra la resignación.

Tercero.- La práctica totalidad de familias estudiadas ha acabado vinculándose, de una u otra manera, a 15M Stop Desahucios. "La plataforma” surgió a finales de 2011, vinculada al $15 \mathrm{M}$ como colectivo de base, para presionar a los bancos con concentraciones ante sus sucursales, parar desalojos y abrir vías de negociación, intentando mostrar a las entidades financieras que, ante un conflicto de tal magnitud, debían valorar la vía negociadora. En los dos últimos años han aumentado los casos de realojos, con un nuevo escenario y unas vías de negociación aún más complejas. El asesoramiento jurídico, el apoyo emocional y la organización de acciones de presión en favor de alquileres sociales continúan activos $\mathrm{y}$ hace que las personas afectadas encuentren un espacio donde compartir problemas; un punto de encuentro de trayectorias muy diversas donde experimentan un tránsito del sufrimiento y la impotencia a la conciencia política y la acción colectiva. Los Grupos de Afinidad y Apoyo Mutuo (GAYAM) han contribuido a que sus participantes asuman que su problema no es particular y aislado, ayudando a combatir la autoinculpación, a compartir vivencias y a socializar y politizar su situación. El apoyo mutuo ha generado y fortalecido un espacio social autónomo para la resistencia emocional, el aprendizaje comunitario y el empoderamiento sociopolítico.

Cuarto.- En varios puntos de Andalucía estas experiencias han supuesto uno de los procesos de politización más intensos de la última década. Este proceso de politización 
de personas aisladas y socialmente desahuciadas en el más amplio sentido del término, en particular las acciones de realojo, constituye un acto de impugnación de sólidas sacralidades sociales y políticas dominantes: propiedad privada, orden público, respeto a la ley... Y ha generado expresiones de transgresión e insubordinación, desde la desobediencia civil y la no violencia activa, ante hechos considerados "injustos". El realojo, individual o colectivo, además de proporcionar "un techo", reivindica la función social de la vivienda y presiona a entidades financieras y administraciones públicas.

Quinto.- Los realojos reasignan además la categoría conceptual de vivienda a inmuebles en desuso pues, "solo el inmueble efectivamente habitado", como sostiene el profesor de la UCO Antonio Manuel Rodríguez, entrevistado en diciembre de 2016, "es susceptible de ser considerado vivienda, poniendo de manifiesto la contradicción inherente a la categoría de vivienda vacía". Dado que la vivienda posibilita otros derechos fundamentales, los realojos devuelven a los inmuebles, habitándolos, su carácter de plataforma facilitadora de tales derechos. La desigualdad legal entre derechos sociales y derechos humanos de un lado, y propiedad privada -y prácticas acaparadoras- de un bien social por otro, se hace patente, dada la negación del derecho a la vivienda como derecho fundamental frente al de propiedad que si lo es.

Sexto.- En Andalucía, la Ley de Función Social de la Vivienda de 2013 generó una fuerte polémica que motivó, además de severas contradicciones políticas en el propio equipo de gobierno autonómico, la declaración de inconstitucionalidad, por recurso interpuesto por el Partido Popular, de algunos de sus artículos; en concreto, de aquellos que preveían sanciones y expropiación de uso para las entidades financieras propietarias que no hicieran efectiva la función social de sus inmuebles. Aunque la Ley de Función Social de la Vivienda haya supuesto una mejora conceptual y legislativa, su capacidad de intervención es limitada, hecho agravado por la inconstitucionalidad declarada de algunos de sus artículos y por la ausencia de compromisos políticos relevantes.

Séptimo.- En los procesos de realojo estudiados, debe ser destacado, de manera específica, el papel desempeñado por las mujeres, como afectadas y en ocasiones también como activistas, llevando la iniciativa en la pareja o al frente de familias monoparentales. En particular, han sido observados casos de mujeres con bajos niveles de instrucción y sin experiencia política o asociativa previa que han destacado por su aprendizaje, por la asunción de liderazgos y por su actividad en reuniones, movilizaciones o procesos de negociación. Durante el trabajo de campo fueron las mujeres quienes mostraron mayor disposición a narrar sus experiencias, siendo ellas se dirigen en primer lugar a la plataforma, las que toman la iniciativa y el impulso inicial. Stop Desahucios está introduciendo en sus fundamentos y en su dinámica organizativa esta componente de género, lo que se traduce, por ejemplo, en contemplar dificultades específicas para la participación social, facilitando horarios y atención a menores en los espacios de reunión, 
fomentando la igualdad y paridad en la representación de la organización, interna y pública y en el desempeño de responsabilidades y otras tareas.

Las mujeres refieren, de manera recurrente, entre sus vivencias personales, sus preocupaciones como madres, asumiendo el realojo como una lucha por procurar a sus hijas e hijos "un techo", y registrándose casos en que se estas mujeres combinan tareas domésticas y atención a hijas e hijos con trabajos irregulares en la economía informal, particularmente la limpieza por horas y con la participación activa en Stop Desahucios. Han experimentado un notorio cambio personal, pasando a asumir roles de ciudadanas activas, política y socialmente comprometidas.

Valgan las palabras del exconcejal delegado de Servicios Sociales en el Ayuntamiento de Córdoba, miembro de la plataforma 15M Stop Desahucios, como cierre a este artículo:

"Yo creo que no es un delito. Yo lo he dicho en prensa y lo diré de nuevo si me preguntan: si mi familia estuviera sin casa y yo fuera a mi administración y no me dieran respuesta, yo ocupaba una casa vacía de un banco. ¿Eso es un delito? Pues yo creo que es más delito permitir que tu familia pase frío en la calle, que tu familia pase hambre" (Rafael del Castillo, exconcejal delegado de Servicios Sociales, Ayuntamiento de Córdoba. Diciembre de 2016). 


\section{REFERENCIAS BIBLIOGRÁFICAS}

Amnistía Internacional España (2015) "Derechos desalojados. El derecho a la vivienda y los desalojos hipotecarios en España”. www.es.amnesty.org. [Consultado el 19 de enero de 2017]

García-Calderón, Israel y Abellán, Jacobo (2016) "El problema de la vivienda en el Madrid neoliberal. Políticas públicas y luchas por la vivienda en el contexto de la crisis urbana”. Working Paper Series Contested Cities. Serie V, Políticas y lucha por la vivienda. [Consultado el 25 de enero de 2017].

Del Romero, Luis (2017) “Diagnóstico del 'cambio'. Valencia”. Proyecto I+D+i PROTO_ LOCAL. De la Protesta a la Propuesta. Ayuntamientos 'del cambio', políticas urbanas y movimientos sociales. Universidad Autónoma de Madrid. Documento de Trabajo, no publicado.

Esping-Andersen, Gosta. (1990) The Three Words of Welfare Capitalism. Cambridge: Princenton University Press.

García-Pérez, Eva y Janoschka, Michael (2016) “Derecho a la vivienda y crisis económica: la vivienda como problema en la actual crisis económica”. Ciudad y Territorio: Estudios territoriales. No 188 , pp. 213 - 228.

Janoschka, Michael (2016) "El problema de la vivienda en la ciudad neoliberal. Políticas públicas y luchas por la vivienda”. Working Paper Series Contested Cities. Serie V, Políticas y lucha por la vivienda. [Consultado el 30 de enero de 2017].

Janoschka, Michael y García-Calderón, Israel (2016) "Viviendas en disputa: ¿espacios de emancipación? Un análisis de las luchas por la vivienda en Madrid”. Historia Actual On line. No 40, pp. 113-127.

Manjavacas, José María; Cerrillo, José Antonio; Luque, Ricardo et al. (2017) "Claves para el estudio del 'cambio' en el ayuntamiento de Córdoba: modelo urbano neoliberal, respuestas sociales y nuevas propuestas municipalistas". Proyecto I+D+i PROTO_LOCAL. De la Protesta a la Propuesta. Ayuntamientos 'del cambio', políticas urbanas y movimientos sociales. Universidad Autónoma de Madrid. Documento de Trabajo, no publicado. Manjavacas, José María (2017) "Familias realojadas en inmuebles propiedad de entidades financieras. Estudios de casos en la ciudad de Córdoba: propiedad de los inmuebles, perfiles sociodemográficos y vivencias de las unidades familiares afectadas". Informe de investigación. Grupo Municipal Ganemos Córdoba - ETNOCÓRDOBA Estudios Socioculturales-Universidad de Córdoba. No publicado. 
Plataforma de Afectados por la Hipoteca (2013) "Obra Social la PAH". http:// afectadosporlahipoteca.com/wp-content/uploads/2013/07/MANUAL-OBRA-SOCIALWEB-ALTA.pdf. [Consultado el 15 de noviembre de 2016]

Oficina Municipal de Defensa de la Vivienda (2016) “Avance Programación”. Informe. Córdoba: OMDV Ayuntamiento de Córdoba. 